\title{
Analysis of wind-photovoltaic-thermal-pumped storage integration system considering carbon emission
}

\author{
Haofei Chen ${ }^{1}$, Huimin Yan $^{2, *}$, Feng $\mathrm{Wu}^{2}$, Tianye Yang ${ }^{2}$, and Yang Shen ${ }^{2}$ \\ ${ }^{1}$ Economic Research Institute, State Grid Jiangsu Electric Power Co., Ltd., Nanjing 210008, China \\ ${ }^{2}$ College of Energy and Electrical Engineering, Hohai University, Nanjing 211100, China
}

\begin{abstract}
This paper presents a new evaluation model of windPhotovoltaic (PV)-thermal-pumped storage integration system considering carbon emission. The model is constructed on the basis of comprehensively considering the construction cost, operation cost, start-up and shutdown cost of the unit, wind abandonment rate, PV abandonment rate and carbon emission cost, and fully utilizing the power curtailments of wind and PV. It analyzes the electric energy benefit and low-carbon economy in three different operation modes including wind-PV-thermal-pumped storage, wind-PV-thermal and thermal under the same load. The effectiveness and rationality of the evaluation method are verified by a simulation example. Combined with the dynamic carbon price, the carbon economy of three different operation modes is analyzed. The analysis results show that windPV-thermal-pumped storage integration system has the best electric energy benefit and carbon economy, and with the increase of carbon price, it has more development prospects.
\end{abstract}

\section{Introduction}

To achieve the target of carbon peak and carbon neutrality, the low-carbon development of energy system is an inevitable trend. Renewable energy plus energy storage is an effective model for low carbonization and flexible development of energy system. In 2020, the total installed capacity of grid-connected wind and solar power generation in China was 119.87 million $\mathrm{kW}$, accounting for $62.8 \%$ of the total installed capacity of new power generation in $2020^{[1]}$. With the rapid development of renewable energy, energy storage technology is especially important. Multi-energy complementary system can maximize the absorption of new energy, improve system reliability, reduce pollutant emissions. How to achieve the maximum power efficiency, and realize the low-carbon operation of energy system is an urgent topic to be studied.

In recent years, scholars at home and abroad have done a lot of research on capacity

configuration, optimal scheduling and economy ${ }^{[2]-[7]}$ of multi-energy complementary systems. Li et al. (2018) [2] established an economic analysis model considering the over interests of power system and energy storage system. Qi et al. (2020) [3] establishes an

*Corresponding author: hhuyhm@vip.sina.com 
economic model of wind-PV-thermal-pumped storage integration system in which the

maximum consumption of wind, photoelectricity and water was taken as the objective function. Zhang et al. (2015) [4] puts forward a new unit commitment model based on costbenefit analysis, which takes into account both the economy and reliability of wind-pumped storage system operation. Li et al. (2009) [5] establishes a quantitative evaluation model of wind-pumped storage integration system considering peak and valley electricity prices. Xie et al. (2019) [6] establishes the economic model of micro-grid planning. Ye et al. (2018) [7] constructs an index framework suitable for evaluating wind-PV-water complementary characteristics. Xiao et al. (2020) [8] and Duan et al. (2015) [9] analyzes the energy saving and emission reduction benefits of renewable energy. However, many literatures do not consider the benefits of carbon emissions, or carry out post-assessment of carbon emissions.

In this paper, a new economic model considering carbon emission is constructed on the basis of considering various costs of wind-PV-thermal-pumped storage integration system. It analyzes the cost-benefit and low-carbon economy in three different operation modes including wind-PV-thermal-pumped storage mode, wind-PV-thermal mode and thermal mode under the condition of having the same load.

\section{Economic model of wind-PV-thermal-pumped storage integration system considering carbon emission}

\subsection{Multi-energy complementary cost evaluation model}

Three regional power grid models (wind-PV-thermal-pumped storage, wind-PV-thermal, thermal) are constructed. Taking the year as the calculation unit.

\subsubsection{The wind-PV-thermal integration system operation (model II)}

(a) on-grid energy

$$
Q_{w p c}=Q_{\text {wind }}\left(1-\theta_{g w}\right)\left(1-\delta_{\text {wind }}\right)+Q_{p v}\left(1-\theta_{g p}\right)\left(1-\delta_{p v}\right)+Q_{c o a l}\left(1-\delta_{c o a l}\right)
$$

where $Q_{\text {wind }}, Q_{p v}, Q_{\text {coal }}$ are the electric energy production of wind farm, PV power station and coal-fired power plant respectively and $\theta_{g w}, \theta_{g p}$ are the abandoned wind rate of wind farm and the abandoned photoelectricity rate of PV power station respectively. $\delta_{\text {wind }}$, $\delta_{p v}, \delta_{c o a l}$ are the station service power consumption rate of wind farm, PV power station and coal-fired power plant respectively.

(b) Operating cost

$$
E_{\text {wpc }}=\left(I_{\text {wind }} r_{\text {wind }}+O_{\text {wind }}\right)+\left(I_{p v} r_{p v}+O_{p v}\right)+\left(I_{\text {coal }} r_{\text {coal }}+O_{\text {coal }}+Q_{\text {coal }} \beta_{\text {coal }} P_{C}\right)
$$

where $I_{\text {wind }}, I_{p v}, I_{\text {coal }}$ are the construction cost of wind farm, PV power station and coalfired power plant respectively. $r_{\text {wind }}, r_{p v}, r_{c o a l}$ are the annual depreciation factor of wind farm, PV power station and coal-fired power plant respectively. $O_{w i n d}, O_{p v}, O_{c o a l}$ are the annual operation cost of wind farm, PV power station and coal-fired power plant respectively. $\beta_{\text {coal }}$ is the coal consumption per unit power generation. $P_{c}$ is the price of coal.

(c) Carbon emission cost

In order to limit and reduce pollutant emissions, the national carbon trading market was officially launched, granting a certain amount of carbon emission quota, and trading the excess part in the market, so as to promote the adjustment of energy structure. 


$$
E_{w p c-c}=Q_{c o a l} \cdot \beta_{c o a l} \cdot B_{i} \cdot \gamma_{i}-e_{w p c-c}
$$

where $B_{i}$ is the environmental value of pollutants. $\gamma_{i}$ is the emission coefficient of pollutants. $e_{w p c-c}$ is the cost of carbon emission quota.

(d) Electrical energy benefit considering carbon emission

$$
\begin{gathered}
A_{w p c}=C_{\text {wind }} Q_{\text {wind }}\left(1-\theta_{g w}\right)\left(1-\delta_{\text {wind }}\right)+C_{p v} Q_{p v}\left(1-\theta_{g p}\right)\left(1-\delta_{p v}\right) \\
+C_{\text {coal }} Q_{\text {coal }}\left(1-\delta_{\text {coal }}\right)-E_{w p c}-E_{w p c-c}
\end{gathered}
$$

where $C_{w i n d}, C_{p v}, C_{c o a l}$ are the on-grid price of wind farm, PV power station and coalfired power plant respectively.

\subsubsection{The wind-PV-thermal-pumped storage integration system operation (model I)}

The integration system operation of wind-PV-thermal-pumped storage is to use abandoned wind and abandoned PV power to pump water in pumped storage power station, which making full use of wind energy and solar energy resources, thus reducing the power generation of thermal power plant, increasing the start-up and shutdown costs of thermal power plant, and realizing the multi-energy complementary effect.

$$
\begin{gathered}
Q_{\text {wind }} \cdot \theta_{g w} \cdot\left(1-\delta_{\text {wind }}\right)+Q_{p v} \cdot \theta_{g p}\left(1-\delta_{p v}\right)=Q_{i n . p} \\
\Delta Q_{\text {coal }}\left(1-\delta_{\text {coal }}\right)=\eta_{p} Q_{i n \cdot p} \\
\Delta C_{o n-o f f}=\Delta B_{o n-o f f} \cdot P_{c}
\end{gathered}
$$

where $Q_{\text {in.p }}$ is the annual power consumption of pumped storage power station when storing water. $\eta_{p}$ is the energy conversion coefficient of pumped storage power station. $\Delta Q_{\text {coal }}$ is the reduced power generation of coal-fired power plant after the construction of pumped storage power station. $\Delta C_{\text {on-off }}$ is the annual new start-up and shutdown costs of coal-fired power plant after the construction of pumped storage power station. $\Delta B_{o n-o f f}$ is the new fuel (standard coal) which is added to start and stop the coal-fired power plant after the construction of pumped storage power station.

(a) Operating cost

$$
\begin{gathered}
\Delta E=\left(I_{p} \cdot r_{p}+O_{p}+C_{i n \cdot p} \cdot Q_{i n . p}\right)-\Delta Q_{c o a l} \cdot \beta_{c o a l} \cdot P_{c}+\Delta B_{o n-o f f} \cdot P_{c} \\
E_{\text {wpch }}=E_{\text {wpc }}+\Delta E
\end{gathered}
$$

where $I_{p}$ is the construction cost of pumped storage power station. $r_{p}$ is the annual depreciation coefficient of pumped storage power station. $E_{w p c}$ is the annual operation cost of pumped storage power station. $C_{i n . p}$ is the pumping electricity price of pumped storage power station.

(b) Carbon emission cost

$$
\Delta E_{c}=\left(-\Delta Q_{\text {coal }} \cdot \beta_{\text {coal }}+\Delta B_{\text {on-off }}\right) B_{i} \gamma_{i}
$$




$$
E_{w p c h-c}=E_{w p c-c}+\Delta E_{c}
$$

(c) Annual electric energy benefit after construction of pumped storage power station

$$
\begin{gathered}
\Delta A=\left[C_{\text {wind }} \cdot Q_{\text {wind }} \cdot \theta_{g w} \cdot\left(1-\delta_{\text {wind }}\right)+C_{p v} \cdot Q_{p v} \cdot \theta_{g p} \cdot\left(1-\delta_{p v}\right)-C_{\text {coal }} \cdot \Delta Q_{\text {coal }} \cdot\left(1-\delta_{\text {coal }}\right)\right. \\
\left.+C_{\text {out.p }} \cdot Q_{\text {out. } . p}-C_{\text {in. } . p} \cdot Q_{\text {in. } . p}\right]-\Delta E-\Delta E_{C} \\
A_{\text {wpch }}=A_{\text {wpc }}+\Delta A
\end{gathered}
$$

where $C_{\text {in.p }}$ is the pumping electricity price of pumped storage power station. $C_{\text {out. }}$ is the on-grid price of pumped storage power station.

\subsubsection{The thermal power plant operation (model III)}

When a thermal power unit operates independently, its generating capacity should meet the demand of the total load, that is, the generating capacity of the thermal power unit should be equal to the total load electricity.

$$
Q_{c}=Q_{f}=Q_{w p c}
$$

(a) Thermal power unit capacity

$$
M_{c}=Q_{w p c} /\left(1-\delta_{\text {coal }}\right) T_{\text {coal }}
$$
loads.

where $T_{\text {coal }}$ is the annual utilization hours of thermal power. $Q_{f}$ is the total capacity of

(b) Operating cost

$$
E_{c}=I_{\text {coal }} r_{\text {coal }}+O_{\text {coal }}+Q_{\text {coal }} \beta_{\text {coal }} P_{c}
$$

(c) Carbon emission cost

$$
E_{c-c}=Q_{\text {coal }} \beta_{c o a l} B_{i} \gamma_{i}-e_{c-c}
$$

where $e_{c-c}$ is the cost of carbon emission quota.

(d) Electrical energy benefit considering carbon emission

$$
\mathrm{A}_{c}=C_{\text {coal }} Q_{\text {coal }}\left(1-\delta_{\text {coal }}\right)-E_{c}-E_{c-c}
$$

\subsection{Evaluation of carbon economy}

\subsubsection{Low carbon contribution rate}

In order to better evaluate the carbon economy of multi-energy complementary system, low-carbon contribution rate was calculated. $u_{c 1}$ is the low-carbon contribution rate of model I relative to model III. $u_{c 2}$ is the low carbon contribution rate of model II relative to model III. The higher the value, the better the carbon reduction benefit. 


$$
\begin{aligned}
& u_{c 1}=\frac{E_{c-c}-E_{w p c h-c}}{E_{c-c}-E_{w p c h-c}+C_{c o a l} Q_{c o a l}\left(1-\delta_{c o a l}\right)} \\
& u_{c 2}=\frac{E_{c-c}-E_{w p c-c}}{E_{c-c}-E_{w p c-c}+C_{c o a l} Q_{c o a l}\left(1-\delta_{c o a l}\right)}
\end{aligned}
$$

\subsubsection{Carbon emission compensation time}

Based on the concept of investment payback period in engineering economics, the carbon emission compensation time is put forward to evaluate the years required for the carbon emission cost to compensate the annual construction cost.

$$
T_{c}=\frac{E_{c}}{Q_{\text {coal }} \cdot \beta_{\text {coal }} \cdot B_{i} \cdot \gamma_{i}}
$$

\section{Analysis of simulation}

\subsection{Multi-Energy Complementary System Structure}

In this paper, a region in northern China is selected as the research background, and the multi-energy complementary system consists of 300MW wind farm, 200MW PV power station, 1000MW thermal power station and 200MW pumped storage power station.

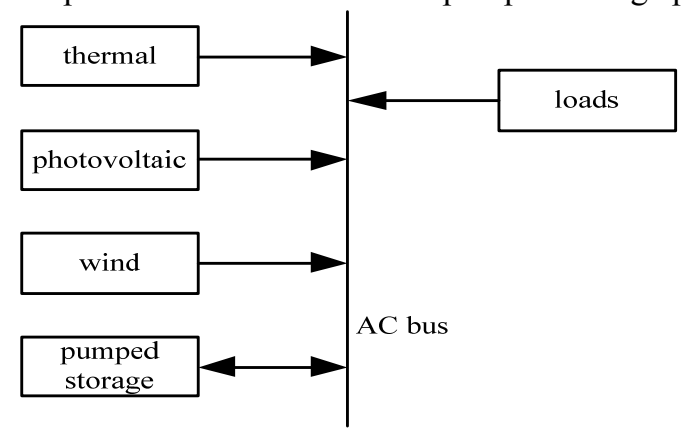

Fig. 1. Wind-PV-thermal-pumped storage integration system

\subsection{Simulation Parameters}

According to the data recommended by the National Development and Reform Commission, $\gamma_{i}$ the emission coefficient of pollutants is $2.62, B_{i}$ the environmental value of pollutants is 0.2 Yuan $/ \mathrm{kg}, \beta_{\text {coal }}$ the coal consumption per unit power generation is 0.32 $\mathrm{kg} / \mathrm{kWh}{ }^{[9]}, P_{c}$ the price of coal is 0.7 Yuan $/ \mathrm{kg}, \Delta B_{\text {on-off }}$ the new fuel (standard coal) which is added to start and stop the coal-fired power plant after the construction of pumped storage power station is 195 yuan/t and $\eta_{p}$ the energy conversion coefficient of pumped storage power station is 0.75 . 
Table 1. System Parameter

\begin{tabular}{|c|c|c|c|c|c|c|c|}
\hline $\begin{array}{l}\text { Unit } \\
\text { Type }\end{array}$ & $\begin{array}{c}\text { Constructi } \\
\text { on } \\
\text { Cost(Yua } \\
\text { n/kW) }\end{array}$ & $\begin{array}{c}\text { Annual } \\
\text { Operation } \\
\text { Cost(Yua } \\
\text { n/kW) }\end{array}$ & $\begin{array}{c}\text { Station } \\
\text { Service } \\
\text { Power } \\
\text { Consumpt } \\
\text { ion }(\%) \\
\end{array}$ & $\begin{array}{c}\text { Abando } \\
\text { ned } \\
\text { Wind } \\
\text { and PV } \\
\text { Rate(\%) }\end{array}$ & $\begin{array}{c}\text { On-grid } \\
\text { Price } \\
\text { (Yuan/k } \\
\text { W) }\end{array}$ & $\begin{array}{l}\text { Annual } \\
\text { Depreci } \\
\text { ation } \\
\text { Factor } \\
(\%) \\
\end{array}$ & $\begin{array}{c}\text { Annual } \\
\text { Utiliza } \\
\text { tion } \\
\text { Time(h } \\
\text { ) }\end{array}$ \\
\hline $\begin{array}{l}\text { wind } \\
\text { farm }\end{array}$ & 6500 & 30 & 3.0 & 20 & 0.61 & 8 & 2000 \\
\hline $\begin{array}{c}\text { PV } \\
\text { station }\end{array}$ & 5400 & 20 & 2.0 & 20 & 0.65 & 8 & 1300 \\
\hline $\begin{array}{l}\text { pumped } \\
\text { storage }\end{array}$ & 4500 & 20 & / & I & $\begin{array}{l}0.85 \text { (on } \\
\text { grid) } \\
0.21 \text { (pu } \\
\text { mping) }\end{array}$ & 7 & 1000 \\
\hline $\begin{array}{c}\text { thermal } \\
\text { plant }\end{array}$ & 3500 & 20 & 2.0 & I & 0.391 & 7 & 3900 \\
\hline
\end{tabular}

\subsection{Result Analysis}

According to the calculation results and Figure 2, Figure 3, Figure 4 and Figure5: In the case of considering carbon emission cost, the annual operating cost from high to low is in the order of Model III > Model I > Model II; the carbon emission cost from high to low is in the order of Model III > Model II > Model I; the electric energy benefit from high to low is in the order of Model I $>$ Model II $>$ Model III. With the increase of carbon price, the carbon emission cost of the three operation modes increases gradually, the electric energy benefit decreases gradually, the low carbon contribution rate rises, the low carbon contribution rate $u_{c 1}$ is higher than the low carbon contribution rate $u_{c 2}$, the carbon emission compensation time decreases, and model I shows a faster decline speed than model II and model III, which shows that model I has better economy and more development prospects.

Table 2. Calculation Results (I wind-PV-thermal-pumped storage system, II wind-PV-thermal system, III thermal system)

\begin{tabular}{|c|c|c|c|c|c|}
\hline Model & $\begin{array}{c}\text { Operation } \\
\text { Cost (Hundred } \\
\text { Million Yuan) }\end{array}$ & $\begin{array}{c}\text { Unit } \\
\text { Operation } \\
\text { Cost (Yuan/ } \\
\mathrm{kWh)}\end{array}$ & $\begin{array}{c}\text { Carbon } \\
\text { Emission Cost } \\
\text { (Hundred } \\
\text { Million Yuan) }\end{array}$ & $\begin{array}{c}\text { Unit Carbon } \\
\text { Emission Cost } \\
\text { (Yuan/kWh) }\end{array}$ & $\begin{array}{c}\text { Electrical } \\
\text { Energy Benefit } \\
\text { (Hundred } \\
\text { Million Yuan) }\end{array}$ \\
\hline I & 15.0760 & 0.3430 & 0.9279 & 0.0211 & 4.0190 \\
\hline II & 13.7400 & 0.3126 & 1.1038 & 0.0251 & 3.9320 \\
\hline III & 15.6400 & 0.3559 & 1.1634 & 0.0265 & -0.2850 \\
\hline
\end{tabular}

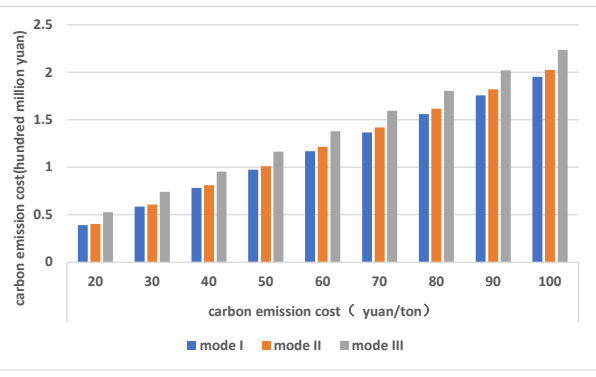

Fig. 2. Impact of carbon price on carbon emission cost

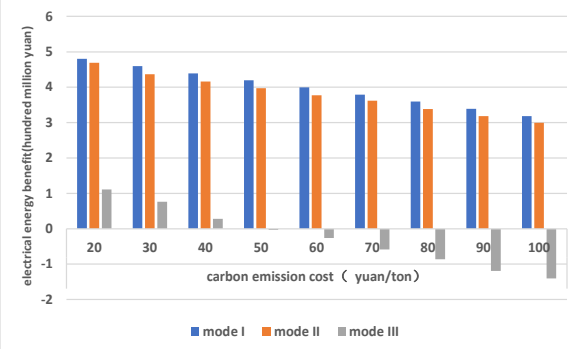

Fig. 3. Impact of carbon price on electrical energy benefit 


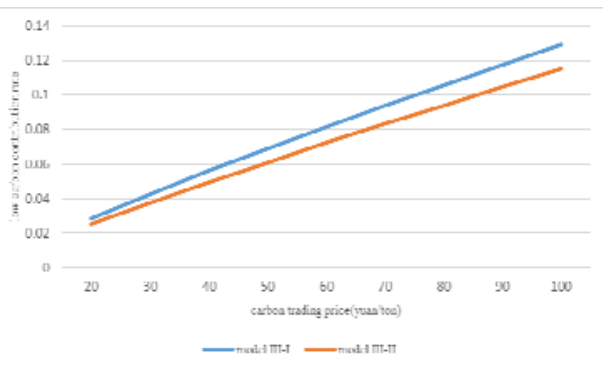

Fig. 4. Impact of carbon price on low carbon contribution rate

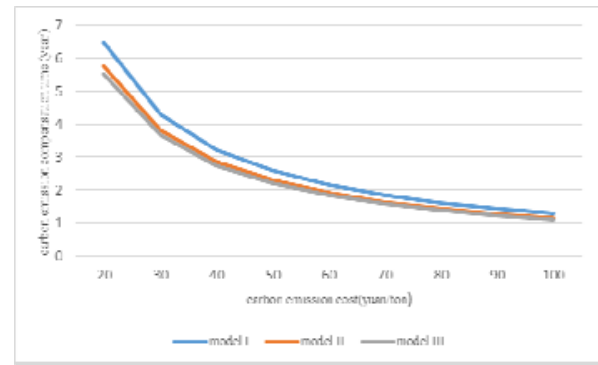

Fig. 5. Impact of carbon price on carbon emission compensation time

\section{Conclusion}

(1) After adding wind power and PV on thermal power plant, the operation cost is reduced by 19.0 million Yuan, the carbon emission cost is reduced by 1.2163 million Yuan, and the electric energy benefit is increased by 42.17 million Yuan. After adding wind power, PV and pumped storage on thermal power plant, the operation cost is reduced by 5.64 million Yuan, the carbon emission cost is reduced by 1.3922 million Yuan, and the electric energy benefit is improved by 43.04 million Yuan. The results show that considering the carbon emission cost, the thermal power plant has the highest carbon emission cost, the highest operating cost and negative electric energy benefit. Wind-PV-thermal-pumped storage system has the lowest carbon emission cost, and its operation cost is higher than that of wind-PV-thermal system, but its electric energy benefit is improved, and it has good economy.

(2) With the increase of carbon price, the cost of carbon emission is gradually increasing, and the carbon emission cost of thermal power is increasing rapidly. The electric energy benefit is gradually decreasing, especially in thermal power plants, where the loss is more serious, and the wind-PV-thermal-pumped storage system has the best electric energy benefit. With the increase of carbon price, the low-carbon contribution rate factor increases, and the low-carbon contribution rate $u_{c 1}$ is higher than the low-carbon contribution rate $u_{c 2}$, the carbon emission compensation time decreases, and the model I shows a rapid decline rate, which shows that the model I (wind-PV-thermal-pumped storage system) has better low carbon economy and development prospects.

(3) In this paper, carbon emissions are included in the cost calculation of electric energy efficiency, which compresses the profits of enterprises. However, with the continuous decline of the cost of new energy, the proportion of new energy in the total energy is increasing, and the profits of enterprises will continue to rise. The model quantifies the power efficiency and carbon economy, which is conducive to guiding the planning and construction of new energy and providing theoretical basis for the system emission reduction scheme.

(4) Peak carbon and carbon neutrality is an energy revolution. At present, up to $51 \%$ of China's carbon emissions come from power generation and heat. Therefore, the energy structure should be adjusted. The launch of carbon trading market can change the energy structure from the supply side and guide users to use low-carbon energy through the price of electricity. In the future, thermal power enterprises are expected to transmit part of the carbon emission cost to the terminal, which will be borne by consumers of electric energy. As a major supplier of carbon dioxide emission reduction such as wind power and photovoltaic, it will definitely increase its income and become the main beneficiary. Therefore, after the operation of the carbon trading market, the carbon price will be coupled 
with the cost of power generation, which will improve the electricity efficiency and promote the transformation of China's energy structure.

\section{Acknowledgements}

This work was supported by National Natural Science Foundation of China (51976053) and Program of Introducing Talents of Discipline to Universities (B14022).

\section{References}

1. X. H. Wang. China Energy Big Data Report (2021)-Electric Power. Electric Power Decision and Public Opinion reference [R], 2021,500 (19).

2. J. H. Li, X. K. Fan, G. Mu, W. C. Ge, Y. F. Ge, D. C. Hu. Economic Analysis Of Energy Storage Applied To Grid Frequency Regulation[J]. Journal Of Global Energy Interconnection, 2018, 1(3): 355-360.

3. Y. Z. Qi, Y. H. Huang, W. S. Wang, Y. F. Wang, X. Y. Pang, C. Zhang, H. T. Zhang. A Study on Hydro-Wind-Solar Consumption Analysis Method For High Proportion of Clean Energy[J]. Power System and Clean Energy, 2020, 36(1): 55-63.

4. L. D. Zhang, M. H. Yin, J. Bu, K. L. Song, Y. Zhou. A Joint Optimal Operation Model of Wind Farms and Pumped Storage Units Based On Cost-Benefit Analysis[J]. Power System Technology, 2015, 39(12): 3386-3392.

5. Q. Li, Y. Yuan, Z. J. Li, W. S. Wang, H. Y. Lu. Research On Energy Shifting Benefits of Hybrid Wind Power and Pumped Hydro Storage System Considering Peak-Valley Electricity Price[J]. Power System Technology, 2009, 33(6): 14-18.

6. H. Xie, X. F. Teng, Y. J. Zhang, T. W. Zhen, L. J. Chen. Analysis Of Economic Influence Factors in Wind-PV-Storage Microgrid[J]. Automation Of Electric Power Systems, 2019, 43(6): 70-76.

7. L. Ye, X. X. Qu, Y. X. Yao, J. T. Zhang, Y. F. Wang, Y. H. Huang, W. S. Wang. Analysis on Intraday Operation Characteristics of Hybrid Wind-Solar-Hydro Power Generation System [J]. Automation Of Electric Power Systems, 2018, 42(4): 158-164.

8. J. W. Xiao, H. X. Huang, X. D. Liu. Carbon Economic Evaluation of Large-scale WindPhotovoltaic-Storage Integration System[J]. Journal of Solar Energy, 2020, 41(6) :171176.

9. J. M. Duan, Z. X. Wang, C. M. Wang, Q. L. Zhou, J. H. Huan. Renewable Power Planning Considering Carbon Emission Reduction Benefits[J]. Power System Technology, 2015, 39(1): 11-15. 